\title{
Critical emancipatory reflection on a practice-based issue in relation to nurses' communicative role with unsatisfied clients in Chinese hospitals
}

Discussion

Chun-Mei Lyu*, Li Zhang

Nursing Administration Department, Foshan Affiliated Hospital of Sun Yat-sen University, Foshan, Guangdong 528000, China

Received: 21 October 2018; Accepted: 12 December 2018; Published: 20 March 2019

Abstract: Objective: This study aims to use reflective theory and critical emancipatory theory to explore nurses' communicative role with unsatisfied clients.

Methods: This paper begins with the broad issue, and the analysis will engage Smyth's cycle, which includes describing, analyzing, exploring, and reconstructing.

Results: Critical emancipatory reflection is essential to make changes in the professional practice of nursing, because it is of primary importance for the professional learning and development of a nurse.

Conclusions: Critical emancipatory reflection helps a nurse to analyze the constraints, including historical, sociocultural, political, and personal aspects.

Keywords: reflective skill • critical emancipatory reflection • Smyth's framework • communication • unsatisfied clients

(c) Shanxi Medical Periodical Press.

\section{Introduction}

Reflection is a form of mental processing. This assignment aims to use reflective theory and critical emancipatory theory to explore my communicative role with unsatisfied clients. For me, the most meaningful and expected outcome is that reflection will improve my professional identity and develop my communication skills in my workplace. This paper will begin with the broad issue, and the analysis will engage Smyth's cycle. ${ }^{1}$ Moreover, there are some reasons why I use critical emancipatory reflection. Firstly, it provides a systematic means of critiquing the power relationships in my workplace. Secondly, it raises awareness and a new sense of informed consciousness to bring about positive social and political change. Thirdly, it will identify misguided perceptions and it can analyze an existing force brought about by the dominating effects of power in human interaction. ${ }^{2}$

My practice story is about my communicative role with unsatisfied clients. Sometimes, I attend meetings between the doctor and patients' family members to communicate further treatment for intensive care unit (ICU) patients. The doctors think that my presence is unnecessary. Owing to poor outcomes, some family

How to cite this article: Lyu CM, Zhang L. Critical emancipatory reflection on a practice-based issue in relation to nurses' communicative role with unsatisfied clients in Chinese hospitals. Front Nurs. 2019; 1: xx-xx. 
members become easily irritated and are disrespectful to me. As a nursing specialist and manager, I know that I need to improve my communication skills in the future. Critical reflection will help me to achieve this.

\section{Methods}

This essay engages Smyth's cycle. A four-stage process of Smyth's reflective framework includes describing, analyzing, exploring, and reconstructing. ${ }^{1}$

\section{Results}

\subsection{Describing}

From my personal experience, respect, collaboration, equality, and knowledge are crucial values in my life. Historically, these values came from my family and work experience. I am the eldest in the family. When I was young, I used to take care of my younger sisters and, therefore, I developed a sense of sharing and respect for one another. Moreover, I have been working in a bigscale hospital for 16 years, and I became a nursing specialist and the manager of ICU in 2009. I am a respected member of the health-care team, especially the nurses, who often seek my assistance in solving complex clinical problems.

According to the Quality Improvement Division, ${ }^{3}$ "patient-centred, safety, effectiveness, timeliness..." have become the new requirements for medical services. To ensure better medical service and patient outcomes, it is crucial to build a multidisciplinary team for patient care and outcome..$^{1,4}$ Collaborating with doctors, therapists, and other medical staff, I believe I can deliver a better patient-focused service. Furthermore, I consider that if I show people how to be respectful, treat others as equal, and work collaboratively, they might treat me in the same way. These mentioned values motivate me to move on.

If there are some unsatisfied clients admitted into the $\mathrm{ICU}$, as a nursing manager, I would follow these cases with the doctors and meet family members in the communication room. However, sometimes, patients' family members prefer to talk to the doctor than to me. I have even experienced worse situations, such as rude behavior from family members. Honestly, I feel embarrassed and upset because they do not respect my knowledge and skills. I would like them to know that I am just as worthy of acknowledgment as doctors. However, I do not think that they would listen to me.

I act according to my belief that the patients' family members and the doctors should respect my opinion. I take part in the communication meeting in order to provide further help for them. However, I feel disappointed that family members might just want to find the most reliable resource from the doctor to change the situation. I am indignant that family members think that only the doctors know everything. In fact, nurses stay with patients for 24 hours in the ICU. Nurses are the ones who complete most of the medical treatments and communicate with the patients. All nurses who work in the ICU are professional and skillful. ${ }^{5}$ Very often, after a doctor had explained the outcome to a patient's family, the nurse would stay for a while to ensure that family members understand the information given and would provide continuous support to them. Nurses observe and communicate with patients, record information of the equipment, and read the human response, including the physical and psychological changes of the patient. ${ }^{5}$ Above all, nurses understand the clients' needs and emotions in the first place. In most cases, I can get this information during the morning ward round. I act as the interface between the family and the hospital system. However, I do not think that patients' family members understand how much effort I have to put in.

As a nursing specialist, I develop my experience and confidence in my work place. In 2008, I received specialist training in Hong Kong. I found that clients respect both nurses and doctors in the hospital of Hong Kong, and I think it should be the same in my ward. Nurses and doctors have different groupings in the work place. ${ }^{6}$ I am pursuing my master's degree in nursing in Ireland, and I notice that Irish nurses have higher social status ${ }^{7}$ than Chinese nurses. ${ }^{8}$ If nurses are treated unfairly, they would easily lose job satisfaction and motivation in the work place, resulting in shortage of nurses. ${ }^{8}$ As a nursing specialist and manager, I have the responsibility to promote work equality among Chinese nurses.

From Fook and Gardner, ${ }^{9}$ critical social theory recognizes that power, or domination, is personally experienced and structurally created. This is because individuals are social beings and their personal characteristics are formed and re-formed during interactions with the real world. ${ }^{9}$ In this sense, I care about respect from my colleagues and clients because I am enthusiastic, possess high educational background, and have rich working experience. Traditionally, nurses seem to be the oppressed group with lower social status, whereas doctors have dominating power. However, the development of nursing care and nurses' professional competencies is aimed at promoting the position of nurses and their social status. ${ }^{10}$ According to the critical social theory, Fook and Gardner ${ }^{9}$ claimed that individuals can take part in their own domination, by holding self-defeating beliefs about their place in the social structure, their own power, and possibilities for change. For me, I want to make an effort to provide effective services for my clients 
and reflect the value of a nurse. I hope doctors and clients can clearly and distinctly recognize the achievement of nurses and eventually change their view of the traditional relationship between the dominant expert and the oppressed nurse.

As reported in previous research, if effective social change is to be achieved, it must occur on both personal and collective levels. ${ }^{9}$ This means that I need to make the change as well as work together with other nurses in order to inform our effort and achievement in the work place. For collective levels, it involves an exchange of views and ideas that consider the perspectives of all the collaborators, irrespective of whether agreement is reached in the interaction. ${ }^{11}$ Additionally, communication and dialogue are the key elements for practices to be effective. ${ }^{12}$ In order to minimize misunderstanding, especially for unsatisfied clients, mutual respect is essential and doctors, nurses, patients and even family members should reach a consensus.

\subsection{Analyzing}

Critical emancipatory reflection helps me to analyze the constraints, including historical, sociocultural, political, and personal aspects. In my experience in a communicative role with unsatisfied clients, family members believed that doctors can use their knowledge to overpower me. I consider that the historical constraints are those that have been perpetuated from many years ago, when doctors were indisputable and no one dared to question them. Historically, doctors have professional power in the hospital hierarchy, and nurses only work as servants to them ${ }^{5}$. Doctors focus on the effectiveness of treatment via physiological parameters. Nurses emphasize caring, such as pain care, skin care, mouth care, wound care, and psychological care. These "clinically superficial" areas of knowledge are perceived and recognized poorly by doctors. ${ }^{5,13}$

Sociocultural constraints also result in this issue. In China, most nurses did not receive higher education for the past decades; they became nurses after graduating from high school. ${ }^{14}$ According to the critical social theory, knowledge comes from empirical and constructed experiences. ${ }^{9}$ Although nurses can get experience from clinical practice, the low implementation levels of educational policies has made it hard to achieve further professional qualifications. This is the reason why I pursued further education abroad, even though I am 38 years old. I believe that by working hard, I can be a role model to young nurses. Meanwhile, a number of medical universities have already set up advanced nursing education programs in China. ${ }^{15}$ Nowadays, clinical nurses have developed their professional knowledge and study further in different specialist areas. As on date, $60 \%$ of nurses in my hospital have qualified with bachelor's degrees. However, I realize that patients and their family members and are still strongly influenced by historical factors. Most people tend to have the mindset that doctors with higher educational background are the only decision-makers. I think that doctors feel it is unnecessary to get help from a nurse in certain situations, even if she is willing to provide assistance. I also think that family members did not see me equally within the hierarchy.

The political constraints are decision-making and division of power in my work place. In clinical practice, doctors and I both use the knowledge gained from the biomedical model of health and illness. I feel that power and authority have been used to preserve the hegemony of the doctor's position in the medical team. However, Coombs and Ersser ${ }^{5}$ found that medical hegemony had become a barrier to interdisciplinary working in the ICU. Moreover, it was reported that hegemony may lead to clinical nurses being unable to take part in the decisionmaking process, and it had fundamental ramifications for multidisciplinary cooperation in the ICU. ${ }^{16}$ The research demonstrated that nurses and doctors used and valued different types of knowledge and adopted different roles in clinical practice..$^{5}$ Generally, nurses take care of the patient for 24 hours a day on a one-to-one level in the ICU. Therefore, nurses should know what is happening to patients as a result of the continuous care. Very often, I found that if some emergency had occurred to a patient, the doctors would speak to family members. As a manager, I always remind the nurses that they should be the ones who contribute the most in terms of updating and providing information on the patient to their family members. In order to ensure that family members can understand the information given by doctors, nurses could provide support whenever help is needed.

Finally, the personal constraints relate to my inability to assert myself in that situation because family members feel unsatisfied with the medical service. I hold the view that whatever I do is right and it is in the best interests of my clients. However, if family members feel unsatisfied, there must be some errors during the provision of medical service. Therefore, I may just act according to my own opinion and may unwittingly disadvantage the service users as a result. Another reason is because I fear being hurt. In China, there are some negative reports about unsatisfied patients acting violently toward medical staff. Hesketh et al. ${ }^{17}$ reported that there were three cases of unsatisfied patients stabbing medical staff in China in March and April 2012 alone. When I saw the report in the media, I was scared whether I would have the same experience. As a result, I lost the confidence to express my own opinion when clients feel angry. I think it is normal to doubt myself at times. I realized that the unsatisfactory outcome is way more than 
my personal inability to make the situation better; rather, it relates to the constraints operating in this situation, such as the social factors, including lack of trust and tendency of violence.

\subsection{Exploring}

Actually, I realized that it is not always possible to live by these values of respect, collaboration, knowledge, and equality in my work setting although I put in these values since I started my work. From then on, I reflected on my previous experience and I started to think differently. I like my job and enjoy having the sense of achievement from my work. It is possible to understand the expectation of patients' family members and predict their demands. Patients' family members are sensitive, vulnerable, and helpless when they are making choices of life and death of the patient. The rude manner in which they used to respond to me could be affected by previous negative experiences or they may just be expressing their emotions. In the Chinese ICU, most doctors and nurses usually work about 10 hours every day. The doctors are very busy in their routine jobs while salvaging the relationship with unsatisfied clients. Thus, nurses are not welcome to join the meeting with the family because it is time consuming for the doctor to discuss the patients' conditions in detail with me before the meeting takes place. Furthermore, the doctors do not want any disagreement from the medical team while communicating with unsatisfied clients, which would lead to misunderstanding and make things worse.

\subsection{Reconstructing}

According to Jarvis, ${ }^{18}$ I need to renew my awareness and communicate actively. Firstly, I am required to develop clinical skills and knowledge over a professional lifetime. Secondly, developing attitudes and attributes allows me to care for and communicate with patients in a sensitive way. Learning communication skills and specific knowledge makes me develop a positive change with reference to my clients and doctors as well. Thirdly, for unsatisfied patients, I should inform the clients some information upon ICU admission, in case they carry a high expectation of recovery for critically ill patients. In China, although there are some negative reports about the poor relationship between patients and health-care providers, Cass et al. ${ }^{19}$ claimed that miscommunication often went unrecognized, including the lack of biomedical knowledge, inappropriate timing, and vague content. It is easy to understand that family members have less biomedical knowledge and have difficulty to accept the poor outcome of their family member. However, as long as I try, there is no limit to what I can achieve to build a harmonious relationship between patient and healthcare provider. On the other hand, there might be someone who feels upset or unsatisfied with my performance regardless of how professional or hardworking I am. It may or may not be my fault, but that is usually not the point. It is important for me to act quickly and according to their wishes. Following some effective measurements, the concerned persons will be more likely to help change their mood and turn that dissatisfaction into satisfaction. Once a negative issue happens, as a manager, I should be ready to lean back and think about nursing management: provide this feedback information to my team, make sure the team members learn from the mistake, and try avoiding it in the future.

\section{Discussion}

I use the emancipatory theory to explore my communicative role with unsatisfied clients. Looking at my practice, different perspectives have been discussed, and I am able to think from another perspective now. From my personal growing environment and working experience, I value the ideas of respect, collaboration, equality, and knowledge. For me, it is crucial to build a multidisciplinary team for patient care and improve the patient outcome. It is believed that I can deliver a better patient-focused service by collaborating with other medical staff. All these values motivate me to move on in my career. Having analyzed the historical, sociocultural, and personal constraints, I now think it is essential to make changes in my professional practice, because it is of primary importance for the professional learning and development of nurses. Furthermore, I seek to free myself from my own assumptions and the oppressive forces that limit my performance. For me, self-validation is a healthy way to view personal and professional boundaries and experience. I believe that developing different perspectives can have a profound impact on why things happened and what can be done to move forward. Critical reflection is a process that allows deep reflection and the questioning of my assumptions and values. Most important of all, it makes me throw away my negative assumptions and make positive change.

\section{Conclusions}

Critical emancipatory reflection helps me to analyze the constraints, including historical, sociocultural, political, and personal aspects. Historically, doctors have professional power in the hospital hierarchy and nurses only worked as servants to them. The sociocultural constraint is due to the fact that everyone has the mindset that only doctors can make decisions. Nowadays, nurses have developed their professional knowledge and further 
study in different specialist areas. However, doctors still occupy the dominant social status. The only thing I can do is keep moving on to pursue further education. The political constraints mainly refer to the division of power. Hegemony is one of the factors due to which I cannot take part in the decision-making process, and it has fundamental ramifications for multidisciplinary cooperation in the ICU. Finally, the personal constraints relate to my inability to assert myself in that situation because family members feel unsatisfied with the medical service. I used to have lesser confidence in dealing with unsatisfied clients because of negative reports from media.

As a nursing manager and specialist, I overlooked these constraints, including cultural, historical, political, and social constraints, throughout my working life. Previously, I always complained about other people who could not understand my job. I feel it is hard to adapt to the working environment until I use emancipatory reflective processes to bring about transformative

\section{References}

1. Smyth J. Developing and sustaining critical reflection in teacher education. J Teach Educ. 1989;40:2-9.

2. Taylor B. Reflective Practice for Healthcare Professionals: A Practical Guide. 3th ed. New York: Open University Press. 2010:79-104.

3. Quality Improvement Division. Framework for Improving Quality in Health Care. Ireland: Health Service Excusive. 2016. https://www.hse.ie/eng/about/who/ qid/framework-for-quality-improvement/framework-forimproving-quality-2016.pdf. Accessed July 31, 2018.

4. The King's Fund. Patient-Centered Leadership: Rediscovering Our Purpose. London: The King's Fund, Center for Creative Leadership. 2013. https:// www.kingsfund.org.uk/publications/patient-centredleadership. Accessed July 31, 2018.

5. Coombs M, Ersser SJ. Medical hegemony in decision-making: a barrier to interdisciplinary working in intensive care. J Adv Nurs. 2004;46:245-252.

6. Chan GW, Ungvari GS, Shek DT, Leung JJ. Hospital and community-based care for patients with chronic schizophrenia in Hong Kong. Soc Psychiatry Psychiatr Epidemiol. 2003;38:196-203.

7. Yeates NA. Dialogue with global care chain analysis: nurse migration in the Irish context. Feminist Rev. 2004;77:79-95.

8. Yun Hu, Jiang AL. Nursing shortage in China: state, causes, and strategy. Nurs Outlook. 2010;58:122-128.

9. Fook J, Gardner F. Practising Critical Reflection: A Resource Handbook. Berkshire, UK: McGraw-Hill Education. 2007:35-37. action. When I go back to China, I know I can think in a different way. Additionally, it is a cycle to use emancipatory theory in reflection because implementing change is a dynamic and ongoing process. Undeniably, some unexpected issues might happen every day. Ideally, I should be aware of the specific problem and its cause and make sure that I learn from my mistakes and try avoiding it the next time. Constant critical reflection can contribute to my role as a nursing specialist and manager, as well as help to develop a professional role. With critical reflection, I can be more confident, be empowered to act, and then transform the theories into practice. I believe that bettering myself by utilizing the experience from my past is crucial for success in the future.

\section{Conflicts of interest}

All contributing authors declare no conflicts of interest.

10. Kuokkanen L, LeinoKilpi H. Power and empowerment in nursing: three theoretical approaches. J Adv Nurs. 2000;31:235-241.

11. Allport FH. A structuronomic conception of behavior: individual and collective: structural theory and the master problem of social psychology. J Abnormal Soc Psychol. 1962;64:3.

12. Habermas J. The Theory of Communicative Active. Boston: Beacon. 1987:235.

13. Armstrong $\mathrm{D}$. The decline of the medical hegemony: a review of government reports during the NHS. Soc Sci Med. 1967;10:157-163.

14. Xu Y, Xu Z, Zhang J. A comparison of nursing education curriculum in China and the United States. $J$ Nurs Educ. 2002;41:310-316.

15. You LM, Ke YY, Zheng J, Wan LH. The development and issues of nursing education in China: a national data analysis. Nurse Educ Today. 2015;35: 310-314.

16. Darvas JA, Hawkins LG. What makes a good intensive care unit: a nursing perspective. Aust Crit Care. 2002;15:77-82.

17. Hesketh T, Wu D, Mao L, Ma N. Violence against doctors in China. BMJ. 2012;345:e5730.

18. Jarvis. Reflective practice and nursing. Nurse Educ Today. 1992;12:174-181.

19. Cass A, Lowell A, Christie $M$, et al. Sharing the true stories: improving communication between Aboriginal patients and healthcare workers. Med J Aust. 2002;176:466-471. 